\title{
The Acoustic Effects of Vowel Equalization Training in Singers
}

Christopher Dromey

Brigham Young University, dromey@byu.edu

Emily Heaton

Brigham Young University

J. Arden Hopkin

Brigham Young University

Follow this and additional works at: https://scholarsarchive.byu.edu/facpub

Part of the Communication Sciences and Disorders Commons

\section{Original Publication Citation}

Dromey, C., Heaton, E. \& Hopkin, J.A. (2011). The acoustic effects of vowel equalization training in singers. Journal of Voice, $25,678-682$.

\section{BYU ScholarsArchive Citation}

Dromey, Christopher; Heaton, Emily; and Hopkin, J. Arden, "The Acoustic Effects of Vowel Equalization Training in Singers" (2011). Faculty Publications. 1784.

https://scholarsarchive.byu.edu/facpub/1784

This Peer-Reviewed Article is brought to you for free and open access by BYU ScholarsArchive. It has been accepted for inclusion in Faculty Publications by an authorized administrator of BYU ScholarsArchive. For more information, please contact ellen_amatangelo@byu.edu. 
The acoustic effects of vowel equalization training in singers

\author{
Christopher Dromey, PhD \\ Emily Heaton, MS \\ J Arden Hopkin, DMA \\ Brigham Young University
}

\author{
Contact Author \\ Christopher Dromey, $\mathrm{PhD}$ \\ Department of Communication Disorders
}

133 John Taylor Building

Brigham Young University

Provo, UT 84602

801.422 .6461 (tel)

801.422 .0197 (fax)

dromey@byu.edu 


\section{Summary}

Vowel equalization is a technique that can be used by singers to achieve a more balanced vocal resonance, or chiaroscuro, by balancing corresponding front and back vowels, which share approximate tongue heights, and also high and low vowels by means of a more neutral or centralized lingual posture. The goal of this single group study was to quantify acoustic changes in vowels following a brief training session in vowel equalization. Fifteen young adults with amateur singing experience sang a passage and sustained isolated vowels both before and after a 15 minute training session in vowel equalization. The first two formants of the target vowels /e,

$\mathrm{i}, \mathrm{a}, \mathrm{o}, \mathrm{u} /$ were measured from microphone recordings. An ANOVA was used to test for changes in formant values following the training session. These formant values mostly changed in a manner reflective of a more central tongue posture. For the sustained vowels, all formant changes suggested a more neutral tongue position following the training session. The vowels in the singing passage mostly changed in the expected direction, with exceptions possibly attributable to coarticulation. The changes in the vowel formants indicated that even a brief training session can result in significant changes in vowel acoustics. Further work to explore the perceptual consequences of vowel equalization is warranted.

Keywords: formant, singing, vowel equalization, chiaroscuro 


\section{INTRODUCTION}

In order to achieve effective vocal projection, experienced singers often make adjustments to the resonating vocal tract to allow an optimal alignment of the fundamental frequency $\left(\mathrm{f}_{0}\right)$ or its harmonics with the formants defined by the vocal tract. Of necessity, there may be compromises in the vowel identity as a result of these altered articulatory postures. ${ }^{1}$ Although the vowels will thus differ acoustically and in some cases even perceptually from their ideal form, this deviation is acceptable in light of the desired artistic benefit of a more powerful voice. $^{2}$

Beyond the need for projection, classically trained singers also strive for a balanced resonance between bright and dark timbres, or chiaroscuro, when they sing. Because adjustments to the vocal tract are responsible for this resonance, the way a singer articulates vowels will consequently be linked to the overall balance of resonance. ${ }^{3}$ The position of the tongue in the mouth directly influences the formant frequencies that identify the vowels a listener hears. The frequency of the first formant (F1) is related to the volume of the pharyngeal cavity, as well as to how tightly the vocal tract is constricted, and depends primarily on tongue height. The frequency of the second formant $(\mathrm{F} 2)$ is related to the length and volume of the resonating space in the oral cavity, which depends mostly on tongue advancement. ${ }^{4}$ The volumes of the pharyngeal and oral cavities are indirectly related to each other during articulation, and are altered as the tongue and the jaw move forward and back, up and down.

Training singers to make adjustments to the vocal tract to enhance the aesthetic quality of their singing often involves instruction in some basic principles of vowel production. ${ }^{5}$ One way to visually represent the relative position of each vowel within the mouth is by using a vowel quadrangle, which displays the vowels in a physiologic relationship in terms of tongue height 
(also jaw opening) and tongue advancement (Figure 1). To help singers achieve the optimal balance of light and dark tones, Hopkin developed a pedagogical technique that replaces the abstract terms of placement, resonance, and projection with more concrete terms and defined articulatory placements. This method, called vowel equalization, offers a means to establish chiaroscuro balance in a sung tone. ${ }^{6}$ Vowel equalization is associated with the use of the vowel quadrangle, and focuses on the five vowels /e, i, a, o, u/.

Hopkin's method involves teaching singers that the closed vowels /i/ and /u/ are produced with contrasting tongue positions (front vs. back), while the jaw position associated with producing each of these vowels is comparable, with an opening between the incisors during singing of approximately $2 \mathrm{~cm}$, which tends to vary somewhat at different pitch and loudness levels. Therefore, these opposite (front-back) vowels are closely related because of their similar height. Likewise, an equivalent relationship exists between /e/ and /o/. The tongue constriction is more forward or backward for these vowels, but the jaw position is shared with approximately a $2.5 \mathrm{~cm}$ distance between the incisors during singing. ${ }^{6}$ In order to equalize these opposite vowels using Hopkin's technique, the singer will quickly glide from one vowel, for example /i/, to the matching vowel, in this case /u/. Only the singer's lips and tongue will move, while the jaw position will remain constant. The vowel equalization technique results in a placement of the tongue for these vowels that involves less movement than is typically employed while producing either vowel in isolation. According to Hopkin, rapid alternation between /i/ and /u/ helps eliminate any unnecessary movement between the two vowels. ${ }^{6}$ Higher and lower vowels are also equalized using this approach, but in this case the extent of tongue raising and lowering is reduced for the vowel pairs $/ \mathrm{i}-\mathrm{a} /, / \mathrm{i}-\mathrm{e} /$, and /e $-\mathrm{a} /$. When producing the $/ \mathrm{i}-\mathrm{e} /$ pair, singers are 
encouraged to hold a relatively stable lingual posture while relying on jaw motion to move between the vowels.

When using this technique, it is anticipated that the perceived vibrations will stabilize in the middle of the mouth as a result of the singer shifting the articulation quickly between the front and back of the mouth. This perception of a more central resonance should indicate to the singer that the vowels are equalized. This vowel equalization approach should thus allow the singer to balance the brightness of front open vowels with the warmth of back closed vowels. As a consequence of these more centralized tongue postures, Hopkin's vowel equalization technique would be anticipated to alter the formants of the singer's vowels away from the more extreme values found in isolated cardinal vowel tokens.

The purpose of the present study was to evaluate the impact of a single session of vowel equalization training on the formant frequencies of vowels produced by a group of undergraduate and graduate amateur singers as they sought to balance the opposite vowels (both front/back and open/closed opposites) in a more neutral articulatory position. Thus, the goal was to provide objective evidence of change following a session of singing instruction. It was hypothesized that following training, F1 and F2 would reflect less extreme articulatory gestures for the vowels at the edge of the quadrangle as singers adopted a more neutral articulatory pattern.

\section{METHODS}

\section{Participants}

Participants included 16 individuals, 7 males and 9 females, who engaged in recreational singing at least one hour per week (such as in a volunteer choir). They ranged in age from 18 to 25 years and had developed varying levels of amateur vocal skill. All participants passed a 
hearing screening, reported no history of voice disorders or persistent articulation disorders beyond elementary school, and were in good general health at the time of the study.

\section{Equipment and Procedure}

Recordings of the singers' voices were made in a sound booth using a head-mounted microphone (AKG C-420) positioned $4 \mathrm{~cm}$ from the mouth. The microphone signal was lowpass filtered at $12 \mathrm{kHz}$ (Frequency Devices 9002) and digitized at $25 \mathrm{kHz}$ with an analog-todigital conversion system (Windaq 720).

Participants were scheduled in groups of 3-4. Following several minutes to allow warmup exercises (specific activities chosen by the singer), each singer was recorded separately as they sang the initial two stanzas of Somewhere Over the Rainbow three times, on a pitch chosen by the participant at a comfortable loudness level. This passage was selected because of the occurrence of each of the five vowels, /a/, /e/, /i/, /o/, and /u/, either as monophthongs or diphthong onsets, within the first two stanzas. After singing the passage, each participant also sustained these vowels in isolation for five seconds, three times each.

Each group of participants then received a brief training in the vowel equalization technique, lasting approximately 15 minutes. First, the singers were coached as they balanced the opposite front and back vowels (/i/ to /u/; /e/ to /o/) by holding a steady jaw position and reducing the extent of front/back tongue movement as they sustained phonation while moving between the two sounds in each set. Next, the participants balanced the opposite open and closed vowels (/i/ to /e/; /u/ to /o/). Following these equalizing exercises, the singers were guided as they attempted to balance /a/ with /e/ and /o/, paying attention to vibratory sensations of the vowels in relation to tongue placement. A more complete description of the vowel equalization 


\section{RESULTS}

Due to technical difficulties (resulting in signal clipping) during one of the recordings, data for 15 of the 16 singers are reported here. The analysis involved a comparison between the pre- and post-instruction measures. The descriptive statistics and repeated measures ANOVA results are summarized in Table 1 for the passage vowels and in Table 2 for the sustained vowel tokens. These results reveal a greater number of significant changes in F2, reflective of changes in the vowels coupled front and back (/i/ to /u/; /e/ to /o/). There were fewer significant changes in $\mathrm{F} 1$ for the vowels that were vertically coupled (/i/ to /a/; /o/ to /a/). 
Vowels from the Singing Passage

Means for both $F_{1}$ and $F_{2}$ for the vowel /a/ decreased significantly following the training in vowel equalization. This suggests that after training the tongue was positioned higher and farther back in the mouth. $\mathrm{F}_{2}$ for the vowels /e/, /i/, and /u/ also decreased significantly following training, indicating a retracted tongue position toward a more neutral placement for vowels /e/ and /i/.

\section{Isolated Vowels}

For the sustained vowels produced in isolation, $\mathrm{F}_{2}$ for /e/ and /i/ decreased significantly following the training session. $\mathrm{F}_{2}$ for the vowel $/ \mathrm{u} /$ increased significantly. $\mathrm{F}_{1}$ for the vowels $/ \mathrm{u} /$ and /i/ increased following training, while $F_{1}$ for the vowel /a/ decreased, but this latter change did not reach significance at the $p<.05$ level. The significant formant changes for each of the vowels produced in isolation suggest a more neutral tongue placement after the training session. Reliability Measures

The data from two of the singers were re-measured by the primary experimenter (EH). The original and re-measured values were highly correlated, with a Pearson $r$ of $.99(p<.001)$. The mean absolute difference between the original and re-measured values was $0.96 \%$.

\section{DISCUSSION}

The goal of the present study was to determine whether a single session of vowel equalization training would influence the formant frequencies of sung vowels. The data reveal a number of significant changes, suggesting that singers may indeed be able to modify their vocal tract configuration in response to training. 
Hopkin's approach to vowel equalization relies on adjustments to opposite vowels. One set of opposite vowels has a similar tongue height, but the vowels differ substantially in their tongue advancement. As /i/ was balanced with /u/ the pre/post formant changes suggest that the tongue advancement for /i/ may have been less extensive, since F2 decreased. For the same pair the tongue for / $\mathrm{u} /$ may have been retracted less, since F2 increased. The equalization of the other front to back coupled vowels would be expected to result in similar formant trends, based on the generally accepted association between lingual postures and the first two formants. ${ }^{4}$ When equalizing /e/ and /o/, $\mathrm{F}_{2}$ of /e/ should decrease, while $\mathrm{F}_{2}$ of /o/ would be predicted to increase. The results of the present study showed that in sustained vowels, the $\mathrm{F}_{2}$ of /e/ did indeed decrease significantly. The $\mathrm{F}_{2}$ of $/ \mathrm{o} /$ increased, but not as substantially (see Table 2).

Another set of opposite vowels has a similar tongue advancement, but they differ in tongue height. Because /i/ and /e/ are both front vowels, they are balanced by decreasing the tongue height for /i/ and increasing the tongue height for /e/. Therefore, $\mathrm{F}_{1}$ for /i/ should increase, while $F_{1}$ for /e/ was expected to decrease. The data reveal that in the passage $F_{1}$ for /e/ increased slightly, but it decreased in the sustained vowel measures. Coarticulatory effects from the sounds preceding and following the production of /e/ may have interfered with the equalization of this vowel. It was expected that these trends would also be found for the posterior opposite vowels $/ \mathrm{o} /$ and $/ \mathrm{u} /$. Indeed, the $\mathrm{F}_{1}$ of $/ \mathrm{u} /$ did increase significantly, while the $\mathrm{F}_{1}$ of $/ \mathrm{o} /$ decreased (to a degree that nearly reached statistical significance), as seen in Tables 1 and 2.

The present results indicate that $F_{2}$ of the sustained vowel /u/ increased significantly following the equalization instruction. This suggests that the tongue may have been advanced further following the vowel equalization training, into a more neutral position. In contrast, $\mathrm{F}_{2}$ for the vowel /u/ from the singing passage decreased significantly from pre- to post-instruction, 
suggesting that the tongue may have been actually more retracted after the training. This is contrary to what would be predicted on the basis of equalization. It is possible that coarticulatory factors in the context of singings words may have contributed to this finding, as each vowel was influenced by the neighboring sounds. The same explanation may also apply to the vowel /a/ in the singing passage. It is possible that during singing, the singers adopted a less fronted lingual posture overall, since F2 for all of the vowels decreased following the training session. In the case of the isolated vowels, all of the significant changes were suggestive of a more neutral tongue placement after training.

\section{CONCLUSION}

A formal perceptual evaluation was not conducted as part of this study. However, even though a number of significant acoustic changes were found following equalization training, the researchers informally observed that the vowels were still produced as the intended sounds. Thus, as the singers altered their articulation, these changes did not seem to be perceptually intrusive. While singing, less extensive articulatory excursions for the opposing vowels should allow quicker articulation shifts in addition to a more consistent resonance balance across the vowels. As suggested by Hopkin ${ }^{6}$, vowel equalization offers a singer an accessible means of developing optimal chiaroscuro. The brightness of the forward vowels blends with the darkness of the back vowels, producing an artistic mixture of the two.

It is possible that vowel equalization may have laryngeal benefits in addition to the resonance balance for vowels. Singing vowels with more extreme lingual excursions may put more tension on the laryngeal musculature because of the tongue's attachment to the hyoid bone, from which the larynx is suspended. The equalization technique may promote relaxation of the 
hyolaryngeal region as front and back vowels are balanced more centrally within the singer's oral cavity. The body of the tongue may thus need less vigorous activation as the forward and backward, higher and lower excursions are reduced. A potential benefit, therefore, is that singing may become more relaxed, although such speculation must remain tentative at this stage.

Given the relatively short training period for this technique and the degree of change in both $F_{1}$ and $F_{2}$, vowel equalization may prove to be a valuable tool for singers of all skill levels. The present study only included 15 amateur or recreational singers. Future research could involve a larger sample of singers with a wider range of singing experience. In the present study post-training performance was recorded a few minutes after the singers learned to equalize their vowels. In future research it may be valuable to learn whether the changes in the first two formants are maintained over time. Follow-up measurements could be taken weeks or even months later to determine whether there are lasting effects from this technique. Additional research could also investigate the impact of a weekly instruction session to reinforce use of the technique and allow the singers multiple exposures to coaching.

One limitation of the present study was that it explored the balancing of front and back opposite vowels (where tongue advancement is the primary difference) more fully than the open and closed opposite vowels. Future studies could examine vowel height adjustments in greater detail. Future work could also profitably examine the nature of the lingual adjustments associated with the vowel equalization technique. Electromagnetic articulography would provide details of tongue movements before and after training. ${ }^{7}$ Alternatively, palatometry could reveal important aspects of linguapalatal contact in singers. ${ }^{8}$ Future work could also evaluate the impact of biofeedback on the process of vowel equalization. For example, a real-time formant tracking 
system that plots $F_{1}$ against $F_{2}$ could provide individual singers the visual feedback necessary to monitor the progress of their equalization while practicing.

Hopkin's vowel equalization technique incorporates the idea of volleying the perceived vibration associated with the front of the mouth to the back of the mouth, and from the upper to the lower regions of the oral cavity, depending on where the tongue is positioned, to a more neutral and centralized sensation. Future research could involve a self-report from the singers regarding the changes in sensation that they experience as they equalize their vowels. It would also be informative to involve expert listeners to qualitatively evaluate singers' vowels before and after the training. Any perceptual changes in singing performance would be important to understand as singers and their vocal teachers strive to develop a more natural and pleasing sound. 


\section{ACKNOWLEDGMENTS}

We express our appreciation to the singers who volunteered to participate in this study and to Dr. Shawn Nissen for his help with data analysis. The project received financial support from the David O. McKay School of Education at Brigham Young University. The study reported here was part of Emily Heaton's master's thesis. 


\section{REFERENCES}

1. Carlsson G, Sundberg J. Formant frequency tuning in singing. J Voice 1992;6: 256-60.

2. Nix J. Vowel modification revisited. J Sing 2004;61: 173-6.

3. Miller R. What about the pure vowel and vowel modification? J Sing 1995;52: 37-40.

4. Sundberg J. The acoustics of the singing voice. Sci Am 1977;236: 82-91.

5. Titze IR. Speaking vowels versus singing vowels. J Sing 1995;52: 41-2.

6. Hopkin JA. Vowel equalization. J Sing 1997;53: 9-14.

7. Schonle PW, Grabe K, Wenig P, Hohne J, Schrader J, Conrad B. Electromagnetic articulography: Use of alternating magnetic fields for tracking movements of multiple points inside and outside the vocal tract. Brain Lang 1987 May;31: 26-35.

8. Dromey C, Sanders M. Intra-speaker variability in palatometric measures of consonant articulation. J Commun Disord 2009 November;42: 397-407. 
Table 1. Means, standard deviations, and ANOVA results for F1 and F2 for the vowels from the singing passage

$\begin{array}{lllllll} & \text { Mean Pre } & \text { SD Pre } & \text { Mean Post } & \text { SD Post } & \text { F-ratio } & p \text {-value } \\ / \mathrm{a} / \mathrm{F}_{1} & 701.7 & 133.9 & 632.7 & 113.6 & 13.40 & 0.003^{* *} \\ / \mathrm{a} / \mathrm{F}_{2} & 1228.6 & 159.0 & 1122.6 & 107.9 & 19.32 & 0.001^{* *} \\ / \mathrm{e} / \mathrm{F}_{1} & 482.5 & 70.4 & 485.5 & 74.9 & 0.058 & 0.813 \\ / \mathrm{e} / \mathrm{F}_{2} & 1954.0 & 233.3 & 1816.2 & 231.1 & 15.583 & 0.001^{* *} \\ / \mathrm{i} / \mathrm{F}_{1} & 328.5 & 56.7 & 331.6 & 52.8 & 0.041 & 0.843 \\ / \mathrm{i} / \mathrm{F}_{2} & 2256.5 & 255.2 & 2126.0 & 207.9 & 10.464 & 0.006^{* *} \\ / \mathrm{o} / \mathrm{F}_{1} & 610.2 & 154.2 & 586.3 & 142.4 & 3.832 & 0.071 \\ / \mathrm{o} / \mathrm{F}_{2} & 1102.6 & 182.5 & 1080.4 & 182.5 & 0.555 & 0.469 \\ / \mathrm{u} / \mathrm{F}_{1} & 307.3 & 44.6 & 309.0 & 37.5 & 0.039 & 0.847 \\ / \mathrm{u} / \mathrm{F}_{2} & 1231.1 & 195.2 & 1163.3 & 151.7 & 7.247 & 0.018^{*}\end{array}$

Note. Degrees of freedom are 1, 14 for ANOVA.

$* p<.05 . * * p .01$. 
Table 2 Means, standard deviations, and ANOVA results for F1 and F2 for the sustained vowels

\begin{tabular}{|c|c|c|c|c|c|c|}
\hline & Mean Pre & SD Pre & Mean Post & $S D$ Post & F-ratio & $p$-value \\
\hline$/ a / F_{1}$ & 683.3 & 135.2 & 622.0 & 122.0 & 4.161 & 0.061 \\
\hline$/ a / F_{2}$ & 1169.8 & 140.6 & 1131.4 & 146.9 & 1.121 & 0.308 \\
\hline$/ e / F_{1}$ & 513.2 & 94.6 & 503.1 & 97.6 & 0.159 & 0.696 \\
\hline$/ e / F_{2}$ & 1942.9 & 266.8 & 1832.4 & 240.1 & 19.989 & $0.001 * *$ \\
\hline$/ \mathrm{i} / \mathrm{F}_{1}$ & 305.9 & 48.1 & 321.5 & 44.0 & 4.180 & 0.060 \\
\hline$/ i / F_{2}$ & 2245.6 & 246.2 & 2121.6 & 222.2 & 9.168 & $0.009 * *$ \\
\hline$/ \mathrm{o} / \mathrm{F}_{1}$ & 502.4 & 68.4 & 501.8 & 82.0 & 0.001 & 0.976 \\
\hline$/ \mathrm{o} / \mathrm{F}_{2}$ & 965.5 & 104.8 & 999.9 & 94.3 & 1.942 & 0.185 \\
\hline$/ \mathrm{u} / \mathrm{F}_{1}$ & 321.6 & 56.8 & 347.7 & 50.7 & 5.797 & $0.030 *$ \\
\hline$/ \mathrm{u} / \mathrm{F}_{2}$ & 1048.7 & 171.4 & 1166.8 & 227.2 & 5.785 & $0.031^{*}$ \\
\hline
\end{tabular}

Note. Degrees of freedom are 1, 14 for ANOVA.

${ }^{*} p<.05 .{ }^{*} p<.01$. 


\section{FIGURE LEGEND}

Figure 1. Vowel quadrangle, showing the relationship between the target vowels for the present study. 
Figure(s)

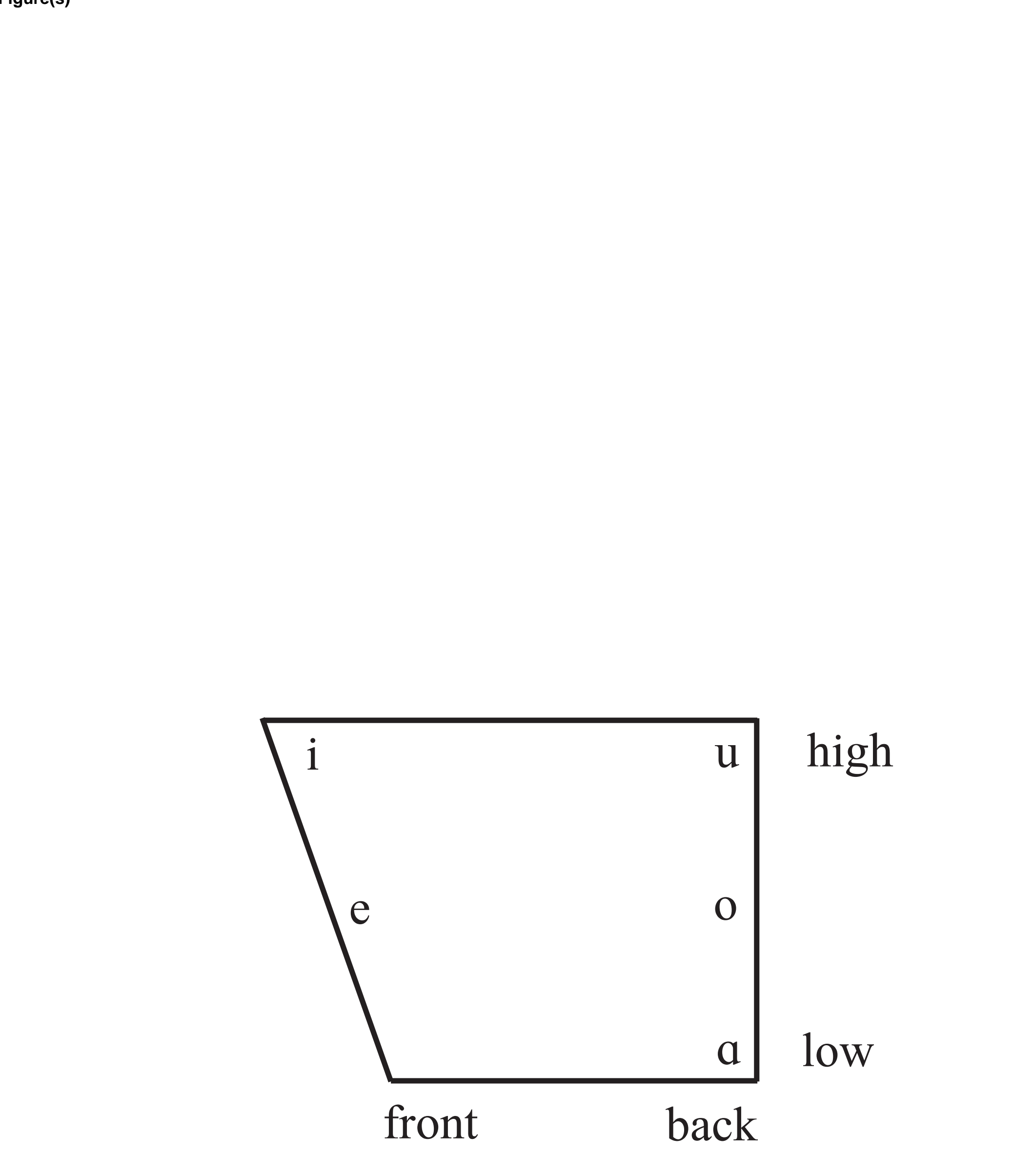

Figure(s) front back

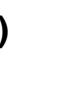

(1)
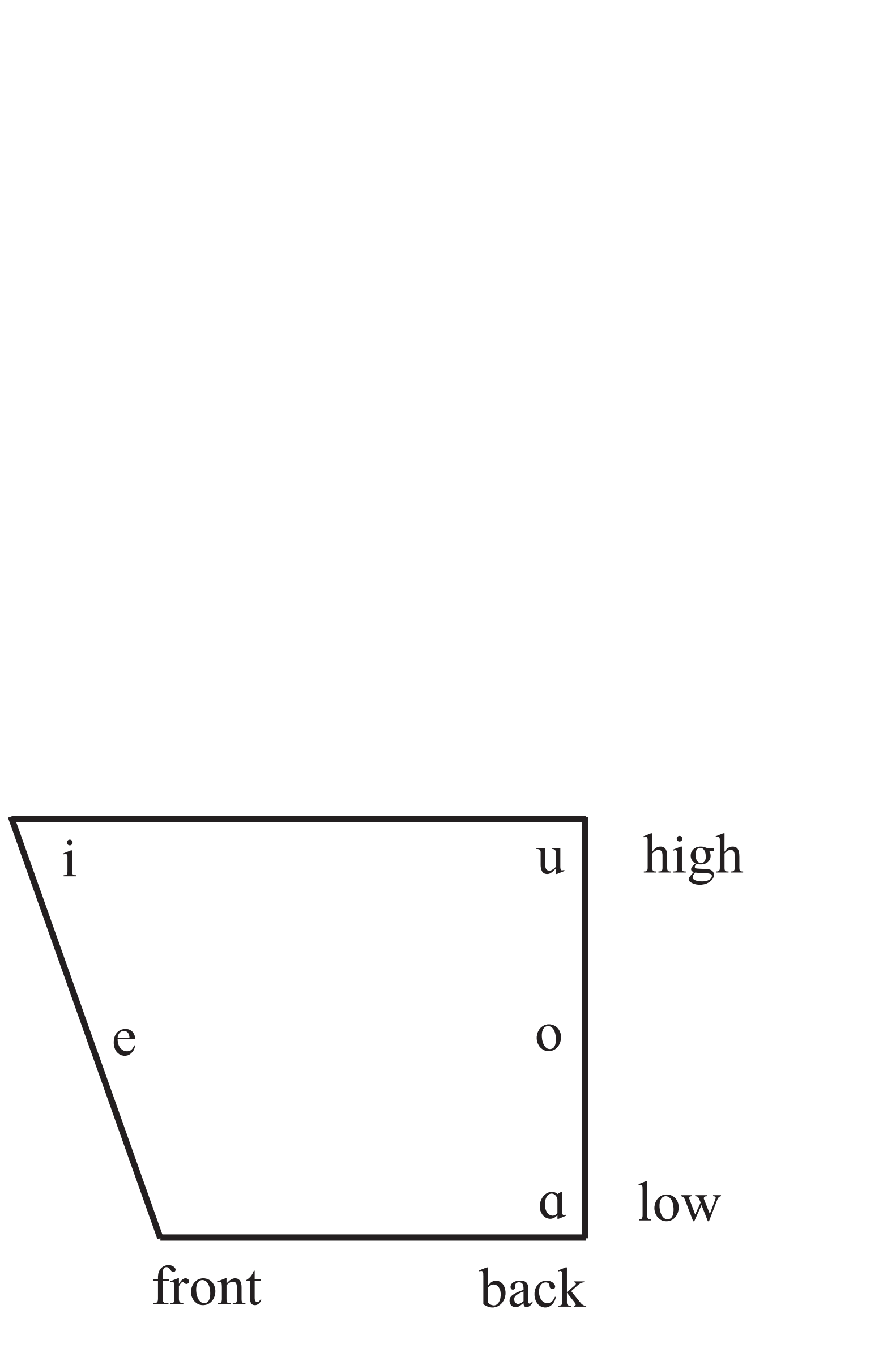

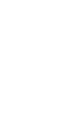

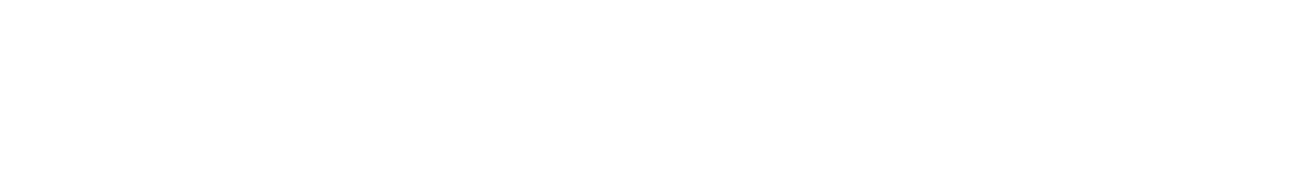

.

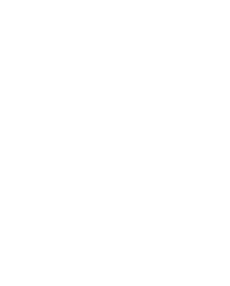

